\title{
A Super-Harmonic Feature Based Updating Method for Crack Identification in Rotors Using a Kriging Surrogate Model
}

\author{
Zhiwen Lu ${ }^{1,2}\left(\right.$, , Yong $\mathrm{Lv}^{1,2, *}$ and Huajiang Ouyang ${ }^{3}$ \\ 1 The Key Laboratory of Metallurgical Equipment and Control of Education Ministry, Wuhan University of \\ Science and Technology, Wuhan 430081, China; jdluzhiwen@163.com \\ 2 Hubei Key Laboratory of Mechanical Transmission and Manufacturing Engineering, Wuhan University of \\ Science and Technology, Wuhan 430081, China \\ 3 School of Engineering, University of Liverpool, Liverpool L69 3GH, UK; h.ouyang@liverpool.ac.uk \\ * Correspondence: lvyong@wust.edu.cn
}

Received: 16 May 2019; Accepted: 12 June 2019; Published: 14 June 2019

\begin{abstract}
Dynamic model updating based on finite element method (FEM) has been widely investigated for structural damage identification, especially for static structures. Despite the substantial advances in this method, the key issue still needs to be addressed to boost its efficiency in practical applications. This paper introduces the updating idea into crack identification for rotating rotors, which has been rarely addressed in the literature. To address the problem, a novel Kriging surrogate model-based FEM updating method is proposed for the breathing crack identification of rotors by using the super-harmonic nonlinear characteristics. In this method, the breathing crack induced nonlinear characteristics from two locations of the rotors are harnessed instead of the traditional linear damage features for more sensitive and accurate breathing crack identification. Moreover, a FEM of a two-disc rotor-bearing system with a response-dependent breathing crack is established, which is partly validated by experiments. In addition, the associated breathing crack induced nonlinear characteristics are investigated and used to construct the objective function of Kriging surrogate model. Finally, the feasibility and the effectiveness of the proposed method are verified by numerical experiments with Gaussian white noise contamination. Results demonstrate that the proposed method is effective, accurate, and robust for breathing crack identification in rotors and is promising for practical engineering applications.
\end{abstract}

Keywords: crack identification; model updating; rotor crack; kriging model; nonlinear characteristics

\section{Introduction}

Rotors are one of the most important components of rotating machines, which are widely used in many engineering fields. Cracks in rotors are a very dangerous kind of fault that may lead to a sudden and catastrophic failure of a rotating machine. Therefore it is of vital significance to monitor and detect a crack, in order to reduce maintenance cost and avoid failure of a rotating machine. In addition, crack parameter identification can provide a foundation for life prediction of a cracked rotor.

A crack in a rotor introduces an additional local flexibility and reduces the overall stiffness. Usually, a fatigue crack in a rotor is a breathing type, which makes the stiffness of such a rotor changing with time and causes the system to become nonlinear. Because of these, a cracked rotor possesses complex dynamic characteristics. Much work on the dynamic behavior of cracked rotors has been performed to identify cracks in rotors, and a number of reviews on this topic [1-7] have been published. From the literature, vibration-based crack identification methods can be broadly classified as model-based 
methods, signal-based methods, modal parameters, and their derivatives-based methods and pattern recognition-based methods.

The approach based on equivalent crack forces is well known as a model-based method for crack identification in rotors, considering the effects of cracks as equivalent forces applied in the intact systems. It has been utilized by Sekhar [8] to identify the crack locations and depths of a rotor with two cracks. Pennacchi et al. [9] further used the approach for cracks identification of a relatively large experiment rig. There are also some other model-based methods. Söffker et al. [10] presented a model-based method based on a proportional-integral observer to identify a crack in an operating rotor. Singh et al. [11] proposed a model-based method to identify a switching crack in a four-degrees-of-freedom Jeffcott rotor utilizing the vibration signal in conjunction with the controller current of the active magnetic bearing. Model-based methods were adopted by Saridakis et al. [12], and Xiang et al. [13] to minimize the difference between real outputs and model outputs to determine the location and depth of a crack in a rotor-bearing system with genetic algorithm (GA). Extended Finite Element methods were developed for cracks and flaws detection and quantification by He et al. [14] and Waisman et al. [15]. Cavalini Jr et al. [16] took nonlinear combinational resonances induced by cracks under external diagnostic forces at certain frequencies as an objective function of a differential evolution optimization method to determine the crack location and depth by minimizing the difference between the measured and modelled rotor systems.

Short Time Fourier Transform (STFT) [17,18], Wavelet Transform (WT) [19-21] and Hilbert-Huang Transform (HHT) [22,23] as signal-based methods, were used to detect a crack from acceleration response of a rotor by Chandra and Sekhar [24]. Approximated Entropy based on information theory was used by Sampaio and Nicoletti [25] to detect rotor cracks considering the interference of misalignment. Full-spectrum method was used to detect a breathing crack in a rotor by Shravankumar and Tiwari [26]. Yang et al. [27] utilized the modulation between crack breathing and vibration response, by using squeezing time-frequency transform (STFT) to extract the periodic oscillation in instantaneous frequency for breathing crack detection. Xie et al. [28] proposed a phase-based spectrum analysis method to extract weak harmonics induced by cracks, to help realize crack detection.

For modal parameters and their derivatives based methods, empirical mode decomposition (EMD) and Laplace wavelet finite element combined method was proposed by Dong et al. [29], to obtain the accurate modal parameters to identify a crack in a rotor. Iterative signal extraction method was utilized to reduce the noise interference in modal parameters identification by Liu et al. [30]. Changes in resonant and anti-resonant frequencies were used by Rubio et al. [31] to detect crack locations in a two-crack torsional shaft. Rahman et al. [32] utilized the changes in phase angle of frequency response function to identify the location and depth of an open crack in a rotor. Seo et al. [33] proposed a method for open crack localization of a shaft by comparing the map of the modal constants of the reverse directional frequency response functions with the reference map of the un-cracked model.

The support vector machine (SVM) is a common pattern recognition-based method with many applications [34], and was used to realize crack identification with features extracted by wavelet transform in [10]. A notch in a stationery rotor was identified by the first four natural frequencies using artificial neural network (ANN) by Zapico-Valle et al. [35].

As a summary for the literature review, there are more crack detection methods than crack identification methods for rotors, and among the crack detection methods, signal based methods are in the majority. These signal based methods can realize crack detection conveniently, while they are difficult in crack parameters identification. For modal parameters based methods, the crack will definitely affect the modal parameters, but the modal parameters are not sensitive to shallow cracks. And for the pattern recognition-based methods, a large amount of crack samples are required to train the models, which limits the application of such kind of methods. For model based methods, they could perform well in crack identification, only if the models were accurate enough. Therefore, the accuracy of a modelling method and efficiency of an identification approach should be the focuses. 
Based on the above short review, there is a trend to transform the crack identification problem into an optimization problem, and through updating iterations to find the crack parameters minimizing the difference between measured features and calculated features, which can be classified as model updating method [36]. The model updating method has been widely used in structural damage identification [37-40], and what matters the most are the model construction and identification efficiency. For the static beam or plate, an accurate model is far more easily to obtain, which will be not the case for rotating rotors, especially when a breathing crack is there. Therefore, how to establish an efficient and reasonable updating model is quite important for crack identification in rotors.

Super-harmonic features are good indicators of a crack in a rotor, which emerge since the presence of a crack leads to asymmetric behaviour and a breathing crack introduces nonlinearity. Although super-harmonic features can also be caused by other faults, such as coupling misalignment which also induces super-harmonics in vibration response of a rotor [41], it is much easier to identify and correct [42]. So in this work only the crack is considered. Energy variation of the $3 \times$ component (where $\mathrm{X}$ represents the frequency corresponding to the rotating speed) extracted based on Wavelet Packet Transform [43-45] was used to quantify the crack depth of a crack with known crack location in a rotor by Gómez et al. [46], and the analytical Jeffcott rotor model and the corresponding experimental rotor with a saw-cut crack were studied to validate the method. EMD method [47-49] was applied to steady-state responses generated from a Jeffcott rotor to extract the $3 \times$ and $2 \times$ components in the neighborhood of $1 / 3$ and $1 / 2$ of the critical rotating speed by Guo et al. [50], results showed that the variation of averaged amplitudes of super-harmonic components provided clear and robust signatures of early cracks in rotating rotors. However, from the literature, few researches have been carried out to identify both the location and depth of a crack in a rotor with these super-harmonic features.

For a cracked rotor system, various crack parameters correspond to various amplitudes of super-harmonic components. For crack localization there must be some spatial information in the corresponding features, therefore, if there is just one measurement point, it is not possible to distinguish the cracks at different locations with varied depths. Hence, more measurement points are needed. In view of the difficulties in taking measurement in rotating rotors, only two points are measured for crack identification. It is believed that two measurement points are enough, only if accurate model information is available. Hence the key to identify a crack in rotors with two measurement points is to obtain a crack model as accurate as possible (it should be noted that the model here is not limited to a structural model but also a mapping between any two variables). However, to obtain an accurate model between crack parameters and features, many samples are required, which will be quite costly and the efficiency will be quite low. Therefore, how to obtain the accurate relationship with much fewer samples and to boost its efficiency are challenges.

A Kriging surrogate model is a statistics-based interpolation method [51]. It has been increasingly utilized in optimization problems in which large computing resources are required [52], and it has also been used in parameter identification [53] and crack identification in plates [54]. However, few applications of Kriging surrogate model have been reported in crack identification in rotors.

In this work, a novel Kriging-based FEM updating method for crack identification for rotors with a breathing crack is proposed using nonlinear super-harmonic features from two "measurement" points, integrating with an improved intelligent optimization algorithm of Particle Swarm Optimization (PSO). The proposed method is effective, accurate and robust for breathing crack identification in rotors and can identify all the crack parameters at the same time, moreover, it is promising for practical engineering applications.

The structure of rest of the paper is organized as follows. Section 2 establishes a model of a two-disc rotor-bearing system with a breathing crack and validates this model by experiment and previous published work. Section 3 carries out the sensitivity analysis of crack parameters to super-harmonic characteristics. Section 4 constructs the Kriging surrogate model that relates crack parameters and super-harmonic features. Section 5 describes the detail of the proposed crack identification method. 
Section 6 presents the numerical simulations and crack identification results. Finally, Section 7 concludes the paper.

\section{Modelling and Validation of a Two-Disc Rotor with a Breathing Crack}

In order to analyze the characteristics of a two-disc rotor with a breathing crack, the finite element method is adopted to establish the model, in which the breathing crack is simulated by the CCLP (crack closure line position) breathing model proposed by Darpe et al. [55]. Since the method has been elaborated in the previous work by the authors [56], here, for the conciseness of the paper, the modelling procedure will just be briefly introduced. Further, validation of the established model is carried out by modal experiment and comparison with previous published work.

Two-node Timoshenko beam elements with six degrees-of-freedom (three translations and three rotations) per node are used to model the rotor-bearing system. Figure 1 shows the two-disc cracked circular rotor-bearing system, the cracked shaft element, and the finite beam element model. To establish the model of the cracked rotor, the key point is to model the crack appropriately and calculate the stiffness matrix of the crack element that can be calculated by the strain energy release rate approach [56]. After that, through assembling the cracked and un-cracked elements, the finite element model of the rotor can be obtained. Though the method is universal for various crack angles, only the transverse crack is considered in this paper in order to simplify the problem.

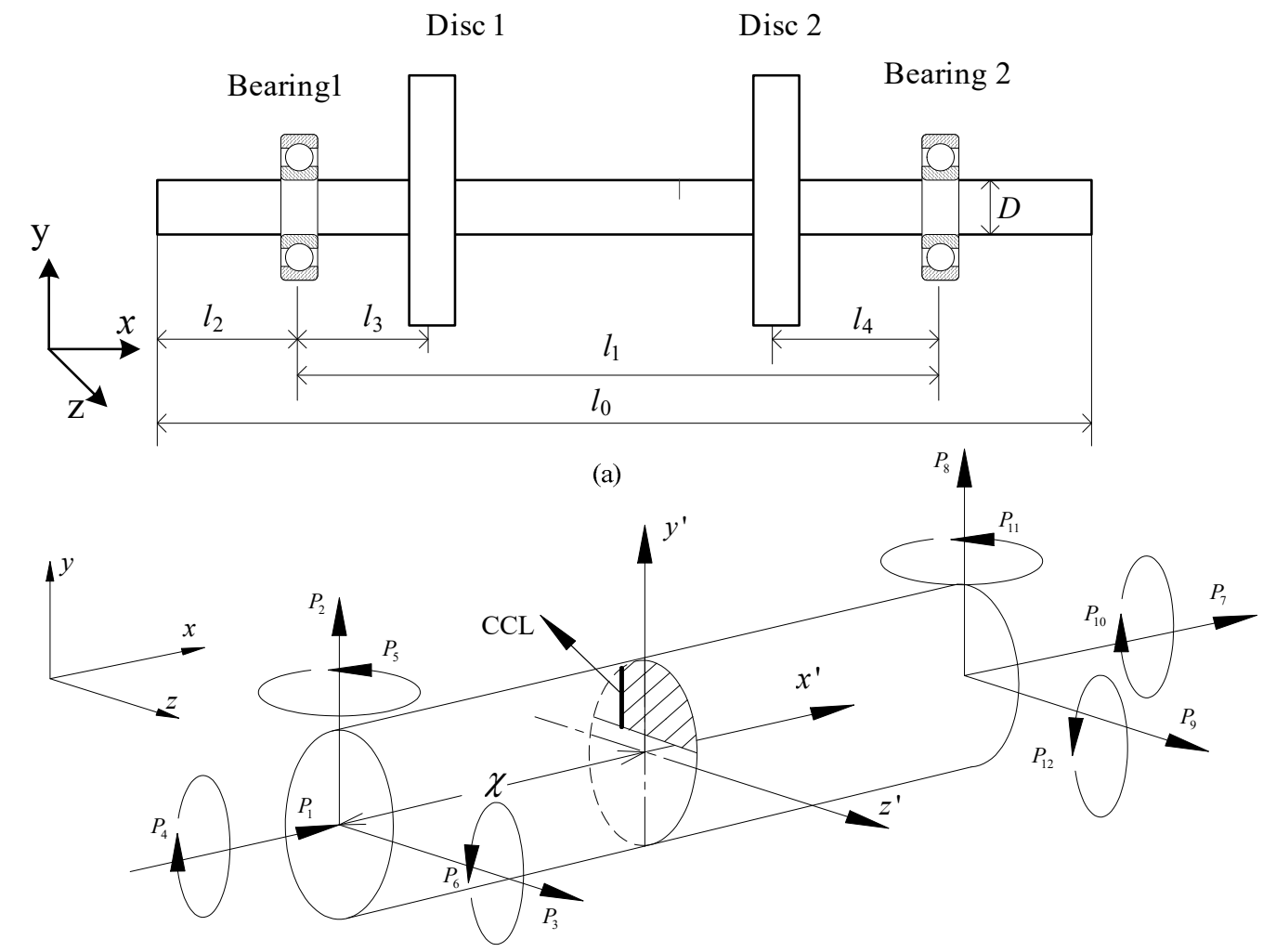

(b)

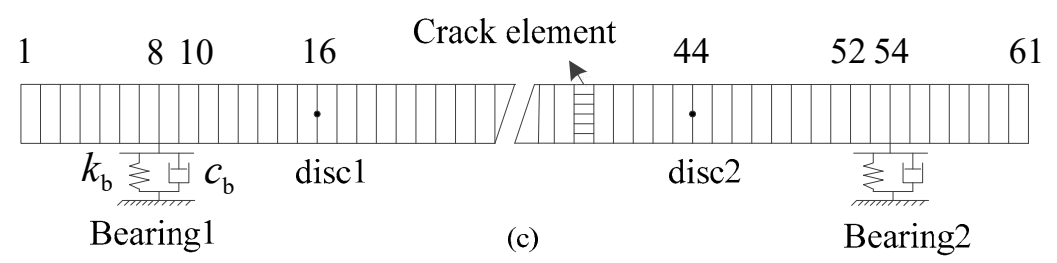

Figure 1. Models of a cracked rotor-bearing system. (a) The cracked two discs rotor-bearing system; (b) the cracked shaft element; (c) the finite beam element model. 
For the rotor in Figure 1a, two discs are considered as rigid bodies, which have three translational and three rotational inertias, and they are added to the mass matrix elements at the corresponding degrees-of-freedom. The gyroscopic effect of the two discs is also included. The bearings are simplified as stiffness and damping systems, both constrain 2 lateral degrees-of-freedom. The rotating speed of the rotor is $\Omega$. By assembling the system matrix of the cracked element and un-cracked elements, the finite element beam model shown in Figure 1c can be established.

Denote $\mathbf{q}_{i}$ as displacement vector of node $i$ having 6 degrees-of-freedom:

$$
\mathbf{q}_{i}=\left\{x_{i}, y_{i}, z_{i}, \theta_{x i}, \theta_{y i}, \theta_{z i}\right\}^{\mathrm{T}}
$$

The equations of motion in the stationary coordinate system can be written as:

$$
\begin{gathered}
\mathbf{M} \ddot{\mathbf{q}}+\left(\mathbf{C}+\Omega \mathbf{G}_{\mathrm{y}}\right) \dot{\mathbf{q}}+\mathbf{K}(t) \mathbf{q}=\mathbf{F}_{\mathrm{e}}+\mathbf{F}_{\mathrm{g}}+\mathbf{F}_{\mathrm{ex}} \\
\mathbf{q}=\left\{\mathbf{q}_{1}, \mathbf{q}_{2}, \ldots \mathbf{q}_{i}, \ldots, \mathbf{q}_{n}\right\}^{\mathrm{T}}
\end{gathered}
$$

where $\mathbf{M}$ is the system mass matrix; $\mathbf{C}=a \mathbf{M}+b \mathbf{K}$ is system damping matrix considering the Rayleigh damping; $\mathbf{G}_{\mathbf{y}}$ is system gyroscopic matrix; $\mathbf{K}$ is system stiffness matrix that will be updated as the crack breathes; $n$ is the total node number (in the following numerical calculation, and the rotor is evenly divided into 60 elements, hence $n$ is equal to 61 ); $F_{e}$ is the excitation due to eccentricity of discs; $F_{g}$ is excitation due to the gravitational force; and $\mathbf{F}_{\mathrm{ex}}$ is external excitation during operation.

Parameters of the rotor-bearing system are shown in Table 1, where $a$ and $b$ are calculated by assuming modal damping ratios of the first two modes being 0.005 and 0.01 .

Table 1. Parameters of the two-disc rotor.

\begin{tabular}{cccc}
\hline Feature & Value (Units) & Feature & Value (Units) \\
\hline Shaft length $\left(l_{0}\right)$ & $0.6 \mathrm{~m}$ & Mass of disc 1 & $0.759 \mathrm{~kg}$ \\
$l_{1}$ & $0.46 \mathrm{~m}$ & polar moment of inertia of disc 1 & $5.758 \times 10^{-4} \mathrm{~kg} \cdot \mathrm{m}^{2}$ \\
$l_{2}$ & $0.07 \mathrm{~m}$ & diametrical moment of inertia of disc 1 & $3.177 \times 10^{-4} \mathrm{~kg} \cdot \mathrm{m}^{2}$ \\
$l_{3}$ & $0.08 \mathrm{~m}$ & Mass of disc 2 & $0.770 \mathrm{~kg}$ \\
$l_{4}$ & $0.1 \mathrm{~m}$ & polar moment of inertia of disc 2 & $5.843 \times 10^{-4} \mathrm{~kg} \cdot \mathrm{m}^{2}$ \\
Shaft diameter $(D)$ & $0.01 \mathrm{~m}$ & diametrical moment of inertia of disc 2 & $3.232 \times 10^{-4} \mathrm{~kg} \cdot \mathrm{m}^{2}$ \\
density (40Cr) & $7.87 \times 10^{3} \mathrm{~kg} \cdot \mathrm{m}^{-3}$ & Gravitational acceleration & $9.8 \mathrm{~m} / \mathrm{s}^{2}$ \\
Yang's modulus & $2.11 \times 10^{11} \mathrm{~Pa}$ & Rayleigh damping coefficient $(a)$ & 0.68 \\
Poisson's ratio & 0.277 & Rayleigh damping coefficient $(b)$ & $2.8 \times 10^{-5}$ \\
\hline
\end{tabular}

To validate the established finite beam element model which called beam model below, on one hand, the intact rotor is established by ABAQUS software, on the other hand, modal experiment by an impact hammer is carried out. The tested rotor is shown in Figure 2, in which two orthogonal eddy current transducers are used to obtain the response excited by the hammer.

The first three natural frequencies are obtained and listed in Table 2. It should be noted that the results from the beam model and ABAQUS software were acquired after a few rounds of model updating iterations by adjusting bearing parameters to make the errors of the first three mode frequencies between ABAQUS and measured ones as small as possible. The corresponding bearing stiffness was found to be $960,000 \mathrm{Nm}^{-1}$, and bearing damping is $100 \mathrm{Nsm}^{-1}$.

As one can see from Table 2, the maximum error between the beam model and ABAQUS was $4.17 \%$, and the error between the beam model and measured results was even less than $2 \%$. The above results show that the established beam model is validated and can be used for further dynamic research. It will be used to study the dynamic behaviors of rotors with cracks, provided that the crack model is accurate. 


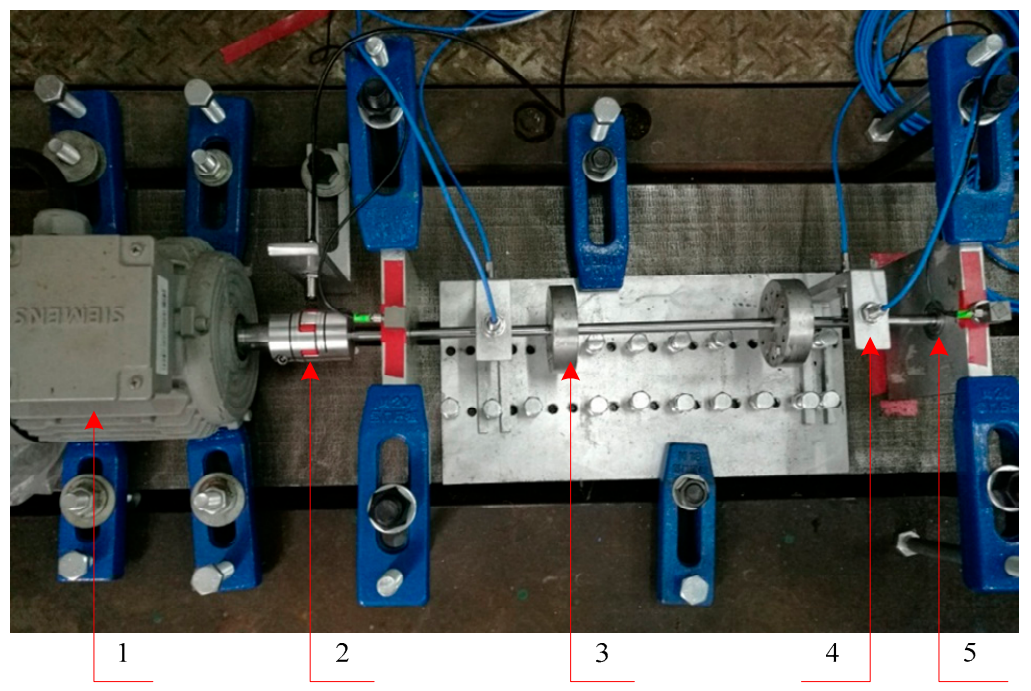

Figure 2. Rotor-bearing system for modal experiment. (1) Motor; (2) flexible coupling; (3) disc; (4) eddy current displacement sensors; (5) bearings.

Table 2. Comparison of the natural frequencies from numerical calculation and experiment.

\begin{tabular}{cccccc}
\hline Order & $\begin{array}{c}\text { Beam } \\
\text { Model }\end{array}$ & ABAQUS & Measured & $\begin{array}{c}\text { Error between } \\
\text { Beam Model } \\
\text { and ABAQUS }\end{array}$ & $\begin{array}{c}\text { Error between } \\
\text { Beam Model and } \\
\text { Measured Results }\end{array}$ \\
\hline 1st vertical bending & $42.1 \mathrm{~Hz}$ & $40.9 \mathrm{~Hz}$ & $42.5 \mathrm{~Hz}$ & $1.2 \mathrm{~Hz}(2.85 \%)$ & $0.4 \mathrm{~Hz}(0.95 \%)$ \\
1st lateral bending & $42.1 \mathrm{~Hz}$ & $41.0 \mathrm{~Hz}$ & $42.9 \mathrm{~Hz}$ & $1.1 \mathrm{~Hz}(2.61 \%)$ & $0.8 \mathrm{~Hz}(1.90 \%)$ \\
2nd vertical bending & $107.9 \mathrm{~Hz}$ & $112.4 \mathrm{~Hz}$ & $107.4 \mathrm{~Hz}$ & $4.5 \mathrm{~Hz}(4.17 \%)$ & $0.5 \mathrm{~Hz}(0.47 \%)$ \\
2nd lateral bending & $107.9 \mathrm{~Hz}$ & $112.4 \mathrm{~Hz}$ & $108.7 \mathrm{~Hz}$ & $4.5 \mathrm{~Hz}(4.17 \%)$ & $0.8 \mathrm{~Hz}(0.74 \%)$ \\
1st torsion & $158.8 \mathrm{~Hz}$ & $160.2 \mathrm{~Hz}$ & - & $1.4 \mathrm{~Hz}(0.88 \%)$ & - \\
3rd vertical bending & $349.6 \mathrm{~Hz}$ & $358.0 \mathrm{~Hz}$ & $349.6 \mathrm{~Hz}$ & $8.4 \mathrm{~Hz}(2.40 \%)$ & $0.0 \mathrm{~Hz}(0.00 \%)$ \\
3rd lateral bending & $349.6 \mathrm{~Hz}$ & $357.2 \mathrm{~Hz}$ & $350.7 \mathrm{~Hz}$ & $7.6 \mathrm{~Hz}(2.17 \%)$ & $1.1 \mathrm{~Hz}(0.31 \%)$ \\
\hline
\end{tabular}

Based on the validated model, the Newmark integration method [57] was adopted to compute the rotor unbalance response after assembling a crack into the rotor by the afore-mentioned crack breathing model. To illustrate the dynamic behavior of the cracked two-disc rotor, a typical waterfall diagram of the cracked rotor (with a crack depth of $0.35 \mathrm{D}$, located in the 30th element) under different rotating speeds below the first critical speed of the rotor is shown in Figure 3.
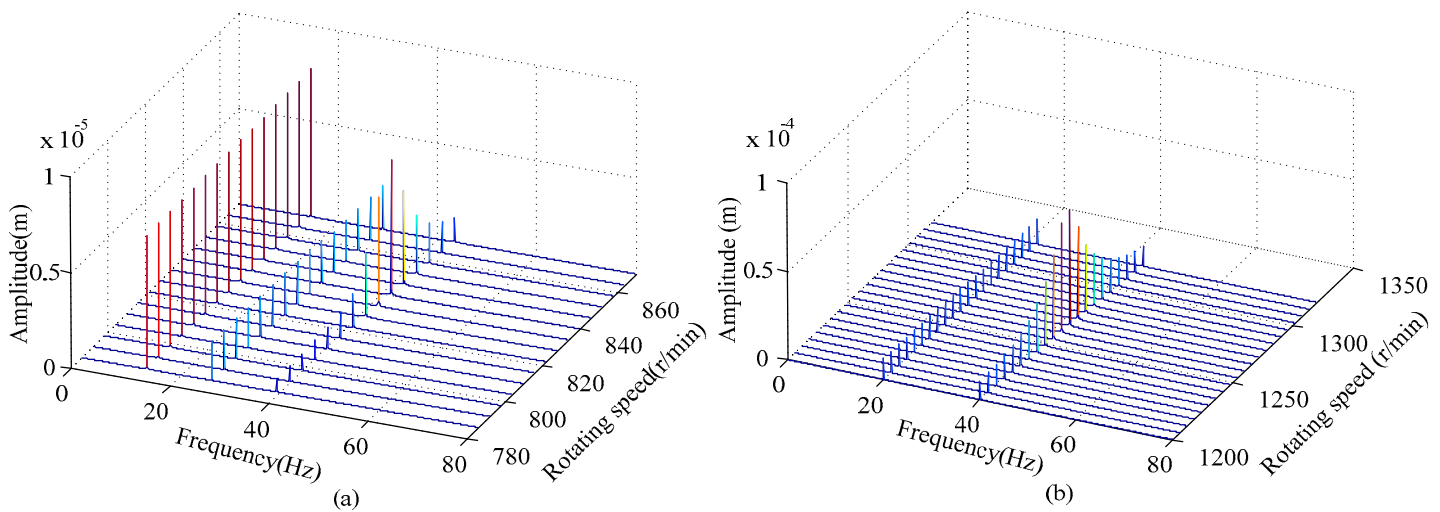

Figure 3. Waterfall diagram of the two-disc rotor (a) rotating speed near $1 / 3$ critical speed; (b) rotating speed near $1 / 2$ critical speed. 
As one can see from Figure 3, 2×, and $3 \times$ super-harmonic components appear and do not exist in an un-cracked rotor, because of crack breathing, which is a nonlinear feature. When the rotating speed reaches $1 / 3$ and $1 / 2$ of the critical speed, the amplitudes of $3 \times$ and $2 \times$ components reach their maximum, respectively. The evolution process of whirl orbits when the rotating speed is at the neighborhood of $1 / 3$ and $1 / 2$ of the critical speed is shown in Figure 4.
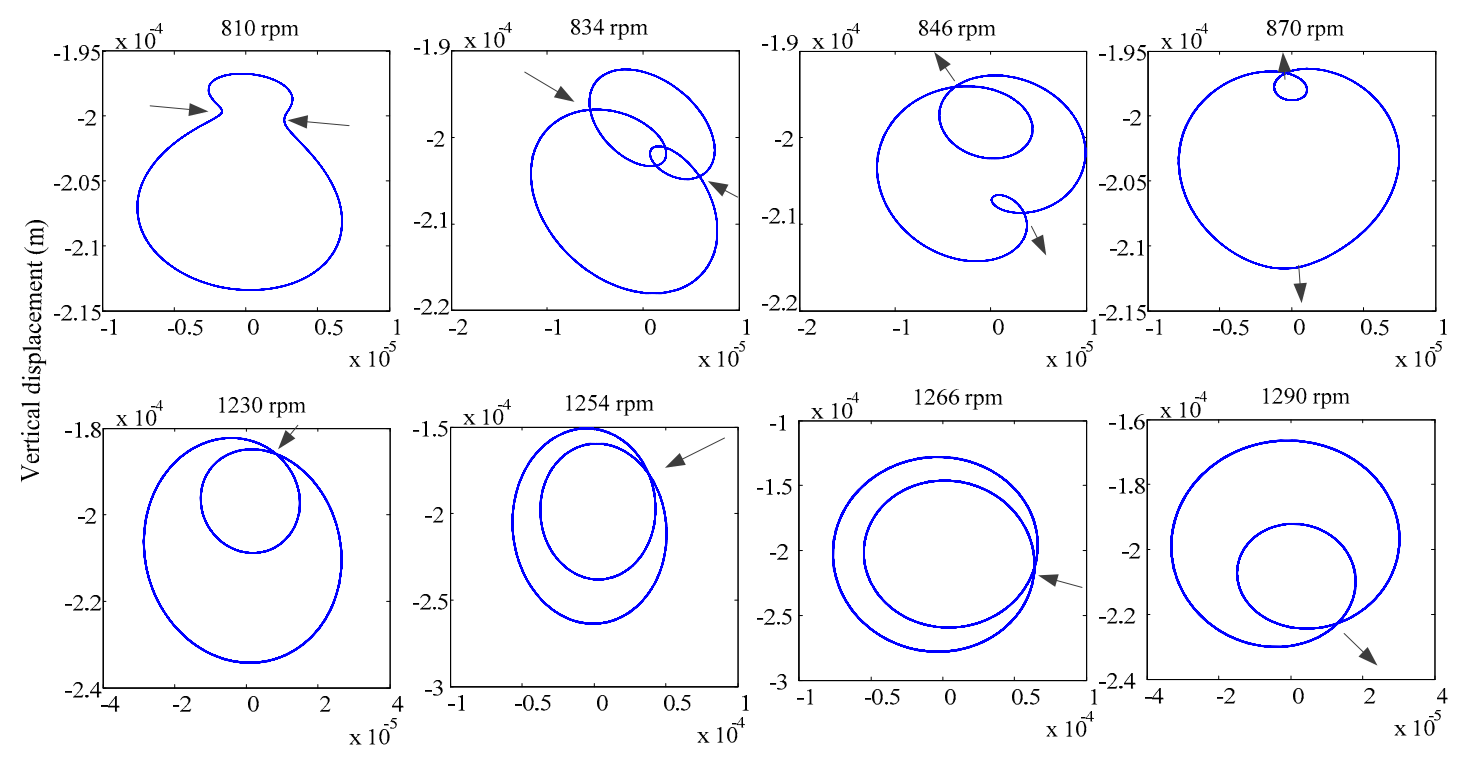

Horizontal displacement $(\mathrm{m})$

Figure 4. Whirl orbits of the cracked rotor in the neighborhood of $1 / 3$ (top row) of and $1 / 2$ (bottom row) of the critical rotating speed.

As for the case near $1 / 3$ critical speed in Figure 4 , the orbits contain two inner loops corresponding to $3 \times$ component, and the loops first grow and become dominant, then after passing through $1 / 3$ critical speed, the loops disappear gradually. In contrast, there is only one inner loop in the orbit corresponding to $2 \times$ component. It almost shares the same evolution trend as the $3 \times$ component. When the rotor passes through $1 / 3$ or $1 / 2$ sub-resonance region, the orbit phase rotates nearly $90^{\circ}$. The behaviors agree with the experiment results in [50] and numerical results in [58], which can verify the correctness of the model and its solution in this paper.

As the model has been established and validated, to study the feasibility and effectiveness of the identification method in theory without interference of other uncertainties in real machines, the crack identification method will be developed and verified based on the validated numerical model of the cracked rotor.

\section{Investigation of the Effects of Crack Parameters on Super-Harmonic Characteristics}

After validating the model of the cracked rotor, to select the most sensitive features to establish the Kriging surrogate model for crack identification, the effects of crack parameters on the super-harmonic components at $1 / 3$ and $1 / 2$ critical speed of the rotor were investigated.

Responses at node 12 were obtained by the established finite element model. The crack location was made to vary from element 10 to 52, which covers the part of the shaft between the two bearings, and crack depth ranges from 0 to $0.45 D$ with step size of $0.05 D$. The numerical simulation results are illustrated in Figure 5 below. 


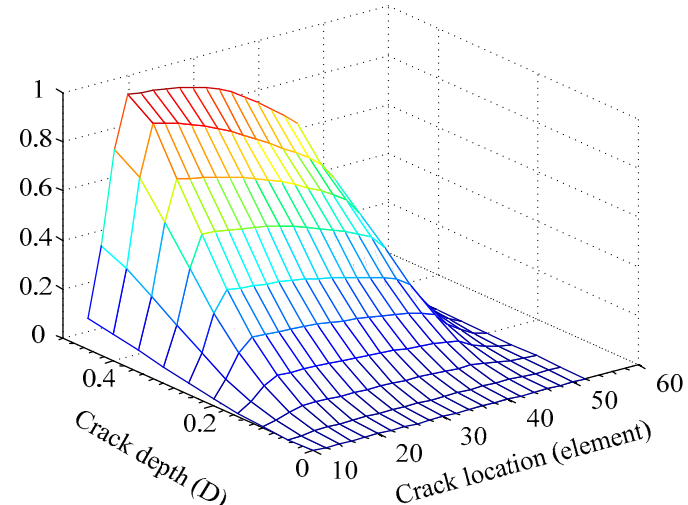

(a)

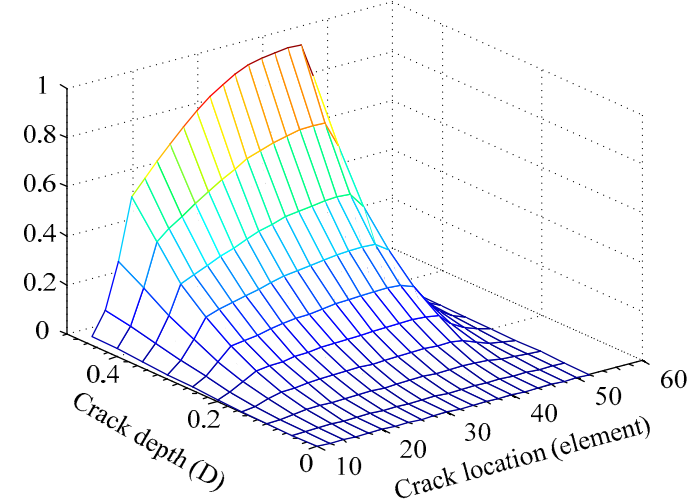

(c)

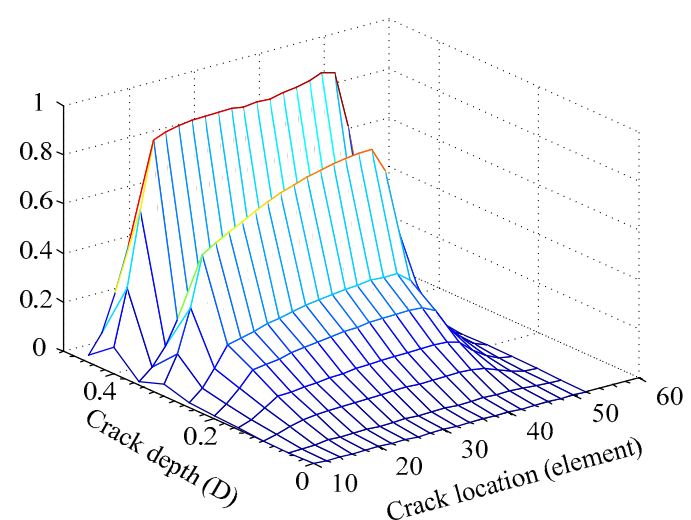

(b)

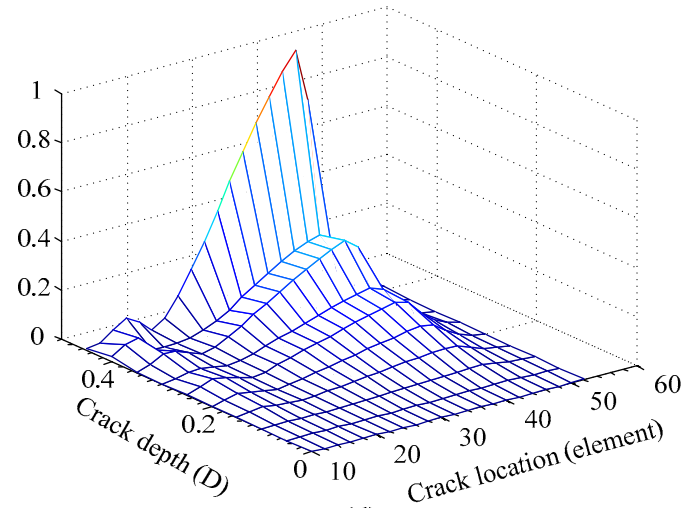

(d)

Figure 5. Normalized amplitudes of super-harmonic components with different crack locations and depths (a) $2 \times$ at $1 / 3$ critical rotating speed; (b) $3 \times$ at $1 / 3$ critical rotating speed; (c) $2 \times$ at $1 / 2$ critical rotating speed; (d) $3 \times$ at $1 / 2$ critical rotating speed.

From Figure $5 a, c$ above, one can see that the amplitudes of $2 \times$ component at $1 / 3$ and $1 / 2$ critical speeds increased monotonously with the increase of crack depths, and they were also distinct between different crack locations. In contrast, the amplitudes of $3 \times$ component at $1 / 3$ and $1 / 2$ critical speeds were not monotonous with the increase of crack depths, which can be seen from Figure $5 b$,d. If the features are monotonous with a crack parameter, then it will be easier to distinct a similar feature value, which will be helpful to reduce the identification errors. Therefore, in view of crack quantification, $2 \times$ components at $1 / 3$ and $1 / 2$ critical speed are better features for crack parameters identification than the $3 \times$ ones.

As the purpose of this paper is to propose a crack identification method for rotors and investigate the feasibility of the method based on a Kriging surrogate model, to simplify the problem, and reduce the demand of input features, only $2 \times$ component at $1 / 3$ critical speed was utilized for crack identification. However, it is difficult to identify a crack from the rotor response at just one measure point, because such a solution may not be unique. To tackle the problem, more measurement points are needed. Considering the difficulties of setting up sensors for rotating rotors, two measurement points were used to determine the crack parameters. Two measurement points should be enough, when the model that maps crack parameters to amplitudes of $2 \times$ components from two measurement points is accurate enough. In view of the accessibility of sensors in real applications, the two measurement points $\mathrm{A}$ and $\mathrm{B}$ were chosen to be node 12 and node 50 respectively in the numerical experiment, which were near the two bearings. Here, it can be said that it is possible to identify the crack in rotors by using the $2 \times$ components from two measurement points. However, the cost of experiment or computation is another important issue which will affect the crack identification efficiency. As the nonlinear breathing crack modelled in this work was response-dependent, computation cost of the simplified beam model was still heavy. Therefore, it is not efficient to utilize the beam model directly combined with an 
optimization method, as the computationally expensive FE models will be called repeatedly during the optimization process. To reduce the cost of experiment or computation in real applications and to avoid the repeated analysis of computationally expensive FE models during the optimization process, a Kriging surrogate model was adopted to establish the accurate relationship with fewer samples, which will be elaborated in the following sections.

\section{Construction of the Crack Kriging Surrogate Model}

A Kriging surrogate model is a statistics-based interpolation method and has been elaborated by Forrester et al. [59]. In this part, the crack Kriging surrogate model will be established for crack identification using the sensitive super-harmonic features. From the sensitive analysis above, the $2 \times$ components at $1 / 3$ critical speed obtained from measurement points $A$ and $B$ will be used for the crack Kriging model construction. The relationship between crack parameters and $2 \times$ amplitudes at $1 / 3$ critical speed can be written as: $\mathbf{Y}=\mathbf{f}(\mathbf{l}, \mathbf{d})=\mathbf{f}(\mathbf{x})$, where, $\mathbf{1}$ and $\mathbf{d}$ are vectors for crack locations and crack depths respectively and $\mathbf{x}$ is the crack parameters set. Specifically, the relationships for measurement points $A$ and $B$ are $\mathbf{Y}^{1}=\mathbf{f}^{1}(\mathbf{l}, \mathbf{d})=\mathbf{f}^{1}(\mathbf{x}), \mathbf{Y}^{2}=\mathbf{f}^{2}(\mathbf{l}, \mathbf{d})=\mathbf{f}^{2}(\mathbf{x})$. Since two measurement points are required, two surrogate models corresponding to measurement points $A$ and $B$ should be constructed, respectively. Details for the crack Kriging surrogate model construction are as follows.

For measurement point A, given $n$ samples of crack parameters and the corresponding $2 \times$ amplitudes:

$$
\mathbf{x}=\left[\begin{array}{c}
\mathbf{x}_{1} \\
\mathbf{x}_{2} \\
\mathbf{x}_{3} \\
\vdots \\
\mathbf{x}_{n}
\end{array}\right]=\left[\begin{array}{cc}
l_{1} & d_{1} \\
l_{2} & d_{2} \\
l_{3} & d_{3} \\
\vdots & \vdots \\
l_{n} & d_{n}
\end{array}\right], \quad \mathbf{Y}^{1}=\left[\begin{array}{c}
y_{1} \\
y_{2} \\
y_{3} \\
\vdots \\
y_{n}
\end{array}\right]
$$

their relationship can be written as a polynomial regression model $F(\boldsymbol{\beta}, \mathbf{x})$ and a normally distributed random process $\epsilon\left(\mathbf{x}_{i}\right)$ with mean value $\mu$ and standard deviation $\sigma$ :

$$
y_{i}\left(\mathbf{x}_{i}\right)=F(\boldsymbol{\beta}, \mathbf{x})+\epsilon\left(\mathbf{x}_{i}\right)
$$

The correlation function between the $i$-th and $j$-th samples is $R\left[\epsilon\left(\mathbf{x}_{i}\right), \epsilon\left(\mathbf{x}_{j}\right)\right]$, which is the Kriging function in this paper. For a $k$-variable design space, a Kriging function can be expressed as:

$$
R\left[\epsilon\left(\mathbf{x}_{i}\right), \epsilon\left(\mathbf{x}_{j}\right)\right]=\exp \left(-\sum_{h=1}^{k} \theta_{h}\left|x_{i}^{h}-x_{j}^{h}\right|^{p_{h}}\right)
$$

where $\theta_{h}$ indicates the sensitivity of the variable $h$ in a sample (as only the location and depth of a crack are involved, therefore $h=1,2$.), and $p_{h}$ determines the smoothness of the correlation function.

The likelihood to eliminate the modelling error can be expressed as a Probability Density Function:

$$
L\left(y_{1}, y_{2}, \cdots, y_{n} \mid \mu, \sigma\right)=\frac{1}{\left(2 \pi \sigma^{2}\right)^{n / 2}|\mathbf{R}|^{1 / 2}} \exp \left(-\frac{\left(\mathbf{Y}^{1}-\mathbf{1} \mu\right)^{\mathrm{T}} \mathbf{R}^{-1}\left(\mathbf{Y}^{1}-\mathbf{1} \mu\right)}{2 \sigma^{2}}\right)
$$

and its logarithmic form is:

$$
\ln (L)=-\frac{n}{2} \ln (2 \pi)-\frac{n}{2} \ln \left(\sigma^{2}\right)-\frac{1}{2} \ln (|\mathbf{R}|)-\frac{\left(\mathbf{Y}^{1}-\mathbf{1} \mu\right)^{\mathrm{T}} \mathbf{R}^{-1}\left(\mathbf{Y}^{1}-\mathbf{1} \mu\right)}{2 \sigma^{2}}
$$


where $\mathbf{R}$ is the correlation matrix of observed samples and $|\cdot|$ is the operator of determinant:

$$
\mathbf{R}=\left(\begin{array}{ccc}
R\left[\epsilon\left(\mathbf{x}_{1}\right), \epsilon\left(\mathbf{x}_{1}\right)\right] & \cdots & R\left[\epsilon\left(\mathbf{x}_{1}\right), \epsilon\left(\mathbf{x}_{n}\right)\right] \\
\vdots & \ddots & \vdots \\
R\left[\epsilon\left(\mathbf{x}_{n}\right), \epsilon\left(\mathbf{x}_{1}\right)\right] & \cdots & R\left[\epsilon\left(\mathbf{x}_{n}\right), \epsilon\left(\mathbf{x}_{n}\right)\right]
\end{array}\right)
$$

Hence, an essential step to construct a surrogate model is to maximize the likelihood. By setting the derivatives of Equation (8) with respect to $Y^{1}$ and $\sigma^{2}$ to zero, one can obtain the most likely values of $\hat{\mu}$ and $\hat{\sigma}$ :

$$
\begin{gathered}
\hat{\mu}=\frac{1^{\mathrm{T}} \mathbf{R}^{-1} \mathbf{Y}^{1}}{1^{\mathrm{T}} \mathbf{R}^{-1} 1} \\
\hat{\sigma}^{2}=\frac{\left(\mathbf{Y}^{1}-\mathbf{1} \hat{\mu}\right)^{\mathrm{T}} \mathbf{R}^{-1}\left(\mathbf{Y}^{1}-\mathbf{1} \hat{\mu}\right)}{n}
\end{gathered}
$$

Then the concentrated likelihood function can be obtained by substituting $\hat{\mu}$ and $\hat{\sigma}$ into Equation (8) and removing the constant term of $-\frac{n}{2} \ln (2 \pi)$ :

$$
\ln (L) \approx-\frac{n}{2} \ln \left(\hat{\sigma}^{2}\right)-\frac{1}{2} \ln |\mathbf{R}|
$$

The value of this function depends on the unknown parameters $\theta$ and $\mathbf{p}$ corresponding to the parameters of the Kriging function in Equation (6), called sensitivity vector of crack parameters and smoothness coefficient vector of correlation function respectively, therefore the problem of constructing the surrogate model is transformed into finding the $\theta$ and $\mathbf{p}$, which maximize the likelihood. The global search method, such as GA, can be used.

Once $\hat{\mu}, \hat{\sigma}, \theta$ and $\mathbf{p}$ are obtained, the $2 \times$ amplitude from measurement point $A$ at an untried point $\mathbf{x}^{*}$ can be predicted based on,

$$
\hat{y}\left(\mathbf{x}^{*}\right)=\hat{\mu}+\mathbf{r}^{\mathrm{T}} \mathbf{R}^{-1}\left(\mathbf{Y}^{1}-\mathbf{1} \hat{\mu}\right)
$$

where $\mathbf{r}$ is the correlation vector between the untried point $\mathbf{x}^{*}$ and the observed data $\mathbf{x}$ :

$$
\mathbf{r}=\left(\begin{array}{c}
R\left[\epsilon\left(\mathbf{x}_{1}\right), \epsilon\left(\mathbf{x}^{*}\right)\right] \\
\vdots \\
R\left[\epsilon\left(\mathbf{x}_{n}\right), \epsilon\left(\mathbf{x}^{*}\right)\right]
\end{array}\right)
$$

Better performance of a Kriging surrogate model requires the fewer prediction error in the entire design space, and the prediction error can be described by [52],

$$
\operatorname{MSE}\left(\mathbf{x}^{*}\right)=\hat{\sigma}^{2}\left[1-\mathbf{r}^{\mathrm{T}} \mathbf{R}^{-1} \mathbf{r}+\frac{\left(1-\mathbf{1}^{\mathrm{T}} \mathbf{R}^{-1} \mathbf{r}\right)^{2}}{\mathbf{1}^{\mathrm{T}} \mathbf{R}^{-1} \mathbf{r}}\right]
$$

To evaluate the prediction error more reasonable, the relative MSE defined by the ratio between MSE and the corresponding amplitude of $2 \times$ component is adopted:

$$
\operatorname{RMSE}\left(\mathbf{x}^{*}\right)=\operatorname{MSE}\left(\mathbf{x}^{*}\right) / \mathbf{Y}\left(\mathbf{x}^{*}\right)
$$

Here, the Kriging model for measurement point A is finished, and the same process is for B. 


\section{Crack Identification Method Based on the Kriging Surrogate Model}

Crack identification is a typical inverse problem. The main idea of the proposed method is to transform the inverse problem into an optimization problem, based on the surrogate model established between crack parameters $\mathbf{x}$ and super-harmonic components $\mathbf{Y}$ from two measurement points. Therefore, crack identification can be stated as:

$$
\left\{\begin{array}{c}
\text { find } \mathbf{x}^{*} \\
\min \left\|\mathbf{Y}_{*}\left(\mathbf{x}^{*}\right)-\mathbf{Y}_{\text {Target }}\right\| \\
\text { subject to } \mathbf{l} \mathbf{b}<\mathbf{x}^{*}<\mathbf{u b}
\end{array}\right.
$$

where, $\mathbf{Y}_{*}$ is the vector of predicted super-harmonic components from two measurement points at the new set of crack parameters $\mathbf{x}^{*} ; \mathbf{Y}_{\text {Target }}$ is the vector of amplitudes of the measured super-harmonic components; and $\mathbf{l b}$ and $\mathbf{u b}$ are vectors of the lower and upper bounds for $\mathbf{x}^{*}$.

As the surrogate model established by the initial samples will not guarantee the accuracy in the entire parameter range, the surrogate model should be updated for the more accurate parameters identification. Therefore, to estimate the accuracy of the surrogate model and identified parameters the following two equations are used:

$$
\begin{aligned}
& C_{1}=1-\frac{\sqrt{\sum_{i}\left(Y_{*}^{i}\left(\mathbf{x}^{*}\right)-Y_{\mathrm{FE}}^{i}\left(\mathbf{x}^{*}\right)\right)^{2}}}{\sqrt{\sum_{i}\left(Y_{\mathrm{FE}}^{i}\left(\mathbf{x}^{*}\right)\right)^{2}}} \\
& C_{2}=1-\frac{\sqrt{\sum_{i}\left(Y_{*}^{i}\left(\mathbf{x}^{*}\right)-Y_{\text {Target }}^{i}\right)^{2}}}{\sqrt{\sum_{i}\left(Y_{\text {Target }}^{i}\right)^{2}}}
\end{aligned}
$$

where, $C_{1}$ is the first criterion to evaluate the accuracy of the current surrogate model; and $C_{2}$ is the second criterion to evaluate the matching degree of the identification results by the current surrogate model. The two criterions are together used to decide whether the current surrogate model needs to be updated or not. $Y_{\mathrm{FE}}^{i}$ is the $i$ th element of $\mathbf{Y}_{\mathrm{FE}}$ with crack parameters $\mathbf{x}^{*}$, where $\mathbf{Y}_{\mathrm{FE}}$ is the super-harmonic features of crack parameters $\mathbf{x}^{*}$ calculated by the finite element model (i.e., the beam model). When the surrogate model and identified parameters do not satisfy the pre-set criterions, the surrogate model should be updated by adding the identified optimal solution in the current iteration, until the criterions are satisfied. Figure 6 illustrates the flowchart of the identification process. It should be noted that the surrogate model is composed of the sub-surrogate models from points $\mathrm{A}$ and $\mathrm{B}$, and during the identification process, surrogate models from points $A$ and $B$ are operating individually to predict the features of untried parameters, and the two models will be merged when evaluating the fitness and the criterions.

To search for the optimal crack parameters based on the surrogate model, global optimization methods, such as GA and Particle Swarm Optimization (PSO), can be used. Compared with GA, PSO utilizes the real coding in optimization and has many merits, such as good robustness and fast convergence rate [60]. In order to enhance the efficiency of PSO, an improved approach based on multi-point adding is proposed. Its main idea is to predict possible solutions in current iteration that the final optimal solution will be nearby, then to add the possible solutions and the optimal solution in the current iteration into the initial swarms for next iteration. The possibility is measured by the distance between the possible solution and the optimal solution in the current iteration. The nearer the distance is, the larger the possibility is. All the added points include three points, the optimal solution, the nearest and the second nearest solutions in the current iteration. 


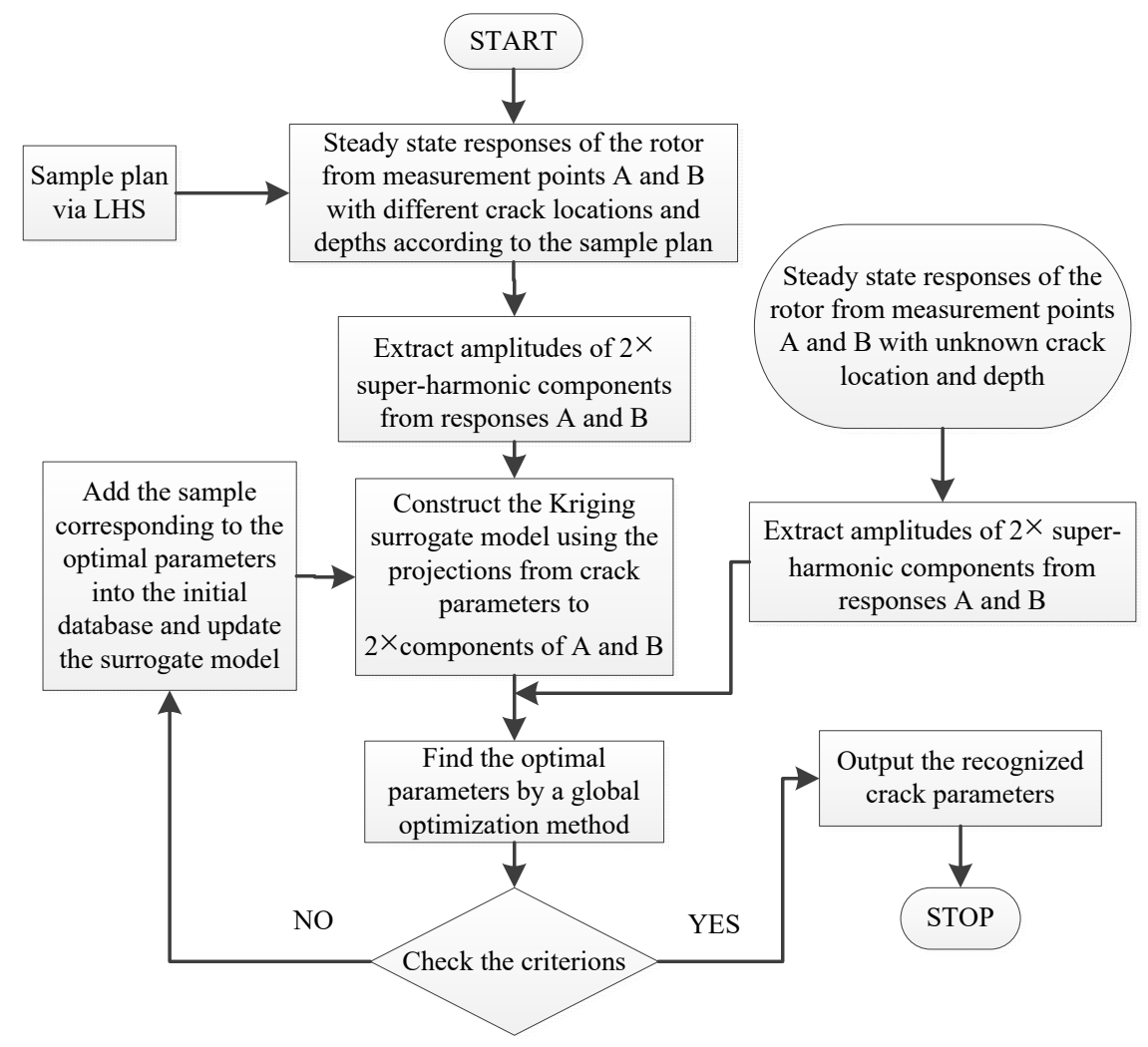

Figure 6. Flowchart of the crack identification method.

\section{Numerical Experiments}

In order to investigate the effectiveness and efficiency of the proposed method, numerical experiments were carried out based on the established cracked rotor finite element model. A sampling plan, as shown in Figure 7, with 20 initial samples generated by Latin Hypercube Sampling (LHS) [52] with crack locations from the 10th element to the 52th element and crack depths in $[0,0.45 D]$ was utilized to construct the surrogate model and identify the crack parameters. Cracks in 10 cases (shown in Figure 7) which cover the typical situations generated by LHS were utilized to test the proposed method.

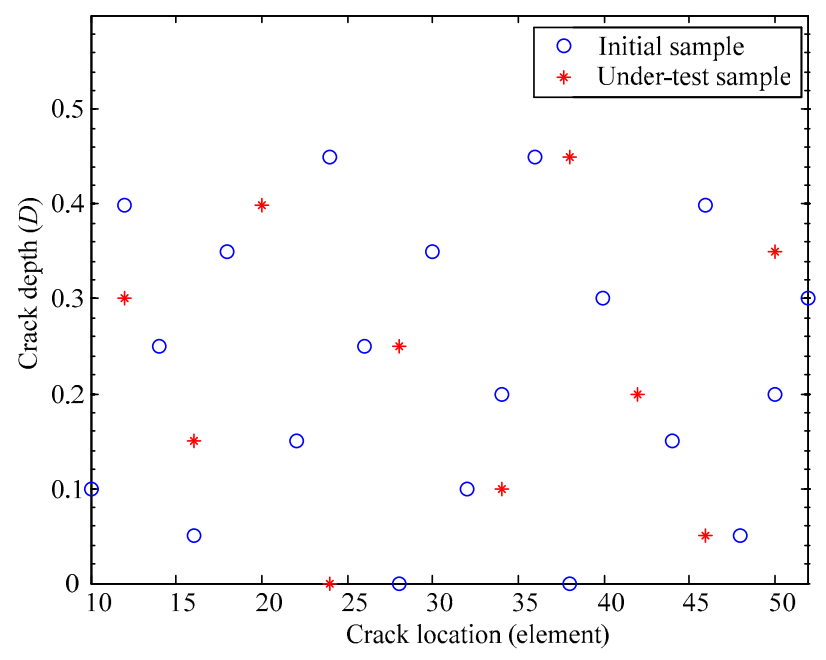

Figure 7. Initial samples and under-test samples. 


\subsection{Prediction Error in the Entire Design Space}

Since the number of initial samples is limited, there will be prediction errors when the current established surrogate model is used to predict new samples, which will affect the accuracy and efficiency of prediction. Therefore, it is important to evaluate the prediction error of the established Kriging model first and to select the proper sample plan. The distribution of prediction error in the entire crack parameters space from the Kriging model of measurement point A is shown in Figure 8, under different sample plans.

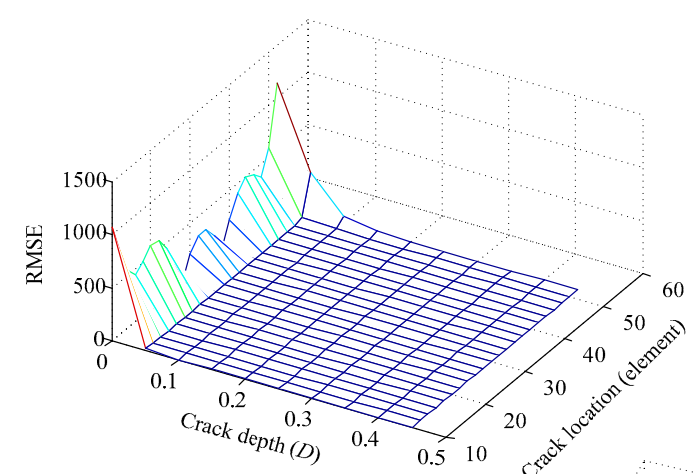

(a)

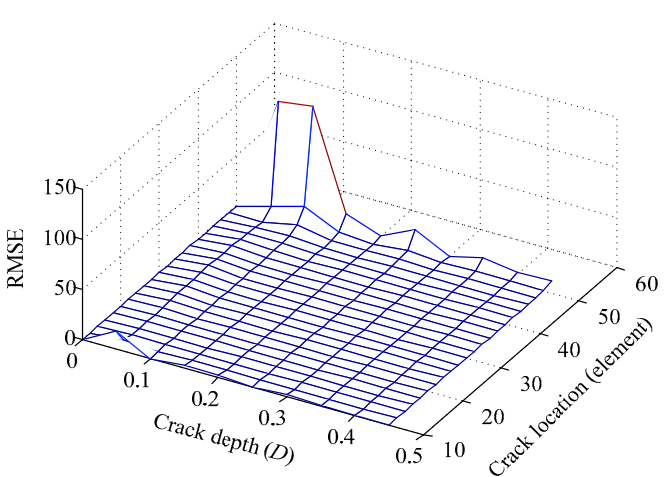

(b)

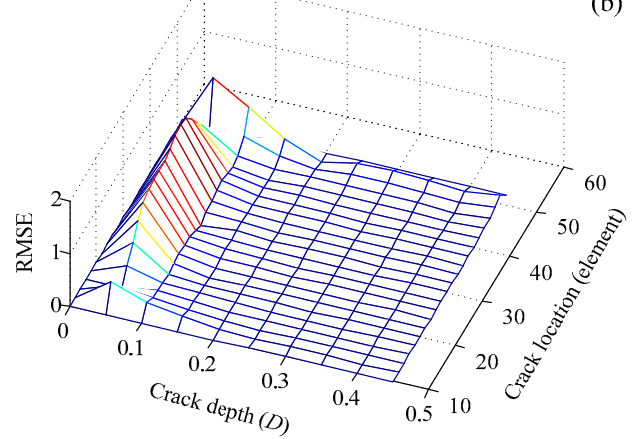

(c)

Figure 8. Distribution of RMSE by the established Kriging surrogate model using various sample sets (a) using initial samples; (b) after adding the samples near boundary the first time; (c) after adding the samples near boundary the second time.

Figure 8a corresponds to the prediction error by the Kriging model established by the initial 20 samples, as shown in Figure 7. From Figure 8a, one can see that the RMSE (the ratio between MSE and the corresponding amplitude of $2 \times$ component) is quite large at the boundary when the crack depth is zero, which means there is a large error when the Kriging model is used to predict sample cases without a crack. In order to improve the prediction performance for no-crack cases, the samples with crack depth zero and crack location ranging from the 10th element to the 52th with a step of 2 elements were added to the initial samples (it should be noted that the added samples are the same case with no crack, however different in mathematic form). The prediction error by the Kriging model re-established is shown in Figure $8 \mathbf{b}$. As one can see from Figure $8 b$, the prediction error was reduced after adding the samples. However, the error was still large at the area where the crack location was near the 52th element. Then, nine new samples with crack location in the 52th element with crack depth varying in the range $[0.05 D: 0.05 D: 0.45 D]$ were added to improve the Kriging model, leading to results in Figure 8c. As shown in Figure 8c, the RMSE in the entire crack parameter space had been much reduced, and the error at the boundary had also dropped considerably. Though the error at the boundary remains large relatively to the inside area, the Kriging model is thought to be acceptable as a reasonable model for crack identification. The prediction error is the major source of identification error, which can be reduced by a bigger sample size. Therefore, there will be a trade-off between the cost and accuracy. 


\subsection{Results of Crack Identification}

After trial and errors, PSO was adopted with the swarm size of 50, the maximum swarm of 100 , and acceleration constants of 1.5 , and criterions of $C_{1} \geq 0.99$ and $C_{2} \geq 0.95$ were used to determine if the updating process should be stopped. Figure 9 and Table 3 are the update process and identification results of the under-test samples in Figure 7. Especially, in Figure 9b, sample 6 was selected as a representative case to show the $\mathbf{Y}_{*}\left(\mathbf{x}^{*}\right)$ evaluated at the optimal solution $x^{*}$ in current iteration compared with $\mathbf{Y}_{\text {Target }}$ of actual parameters.

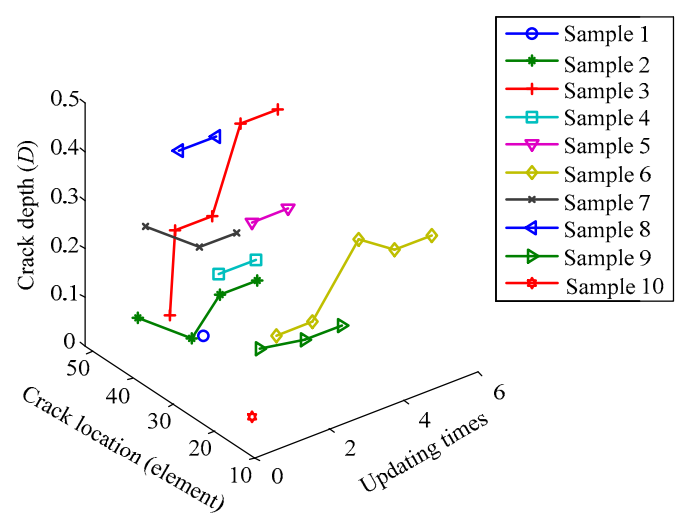

(a)

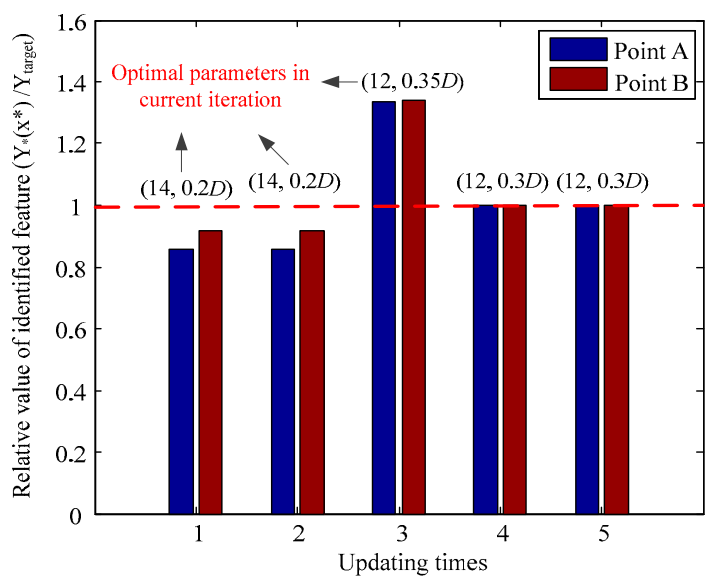

(b)

Figure 9. Update process of the under-test samples. (a) Identification process for all samples; (b) identification process and corresponding value of identified feature for sample 6.

Table 3. Crack identification results of the under-test samples.

\begin{tabular}{|c|c|c|c|c|c|c|}
\hline \multirow[b]{2}{*}{$\begin{array}{c}\text { Under-Test } \\
\text { Sample } \\
\text { Number }\end{array}$} & \multicolumn{2}{|c|}{ Actual Parameters } & \multicolumn{2}{|c|}{ Identified Results } & \multirow[b]{2}{*}{$\begin{array}{l}\text { Updating } \\
\text { Times }\end{array}$} & \multirow{2}{*}{$\begin{array}{c}\text { Criterion Values } \\
\text { for the Final } \\
\text { Updated Model } \\
\left(C_{1}, C_{2}\right)\end{array}$} \\
\hline & $\begin{array}{c}\text { Crack } \\
\text { Location } \\
\text { (Element) }\end{array}$ & $\begin{array}{c}\text { Crack } \\
\text { Depth }(D)\end{array}$ & $\begin{array}{c}\text { Crack } \\
\text { Location } \\
\text { (Element) }\end{array}$ & $\begin{array}{c}\text { Crack } \\
\text { Depth }(D)\end{array}$ & & \\
\hline 1 & 34 & 0.1 & 32 & 0.1 & 1 & $(1,0.96)$ \\
\hline 2 & 46 & 0.05 & 46 & 0.05 & 4 & $(1,1)$ \\
\hline 3 & 50 & 0.35 & 50 & 0.35 & 5 & $(1,1)$ \\
\hline 4 & 28 & 0.25 & 28 & 0.25 & 2 & $(1,1)$ \\
\hline 5 & 20 & 0.4 & 20 & 0.4 & 2 & $(0.99,0.99)$ \\
\hline 6 & 12 & 0.3 & 12 & 0.3 & 5 & $(1,1)$ \\
\hline 7 & 42 & 0.2 & 42 & 0.2 & 3 & $(1,1)$ \\
\hline 8 & 38 & 0.45 & 38 & 0.45 & 2 & $(1,1)$ \\
\hline 9 & 16 & 0.15 & 16 & 0.15 & 3 & $(1,1)$ \\
\hline 10 & 24 & 0 & 28 & 0 & 1 & $(1,1)$ \\
\hline
\end{tabular}

As the samples in the initial sampling plan and the samples added to update the surrogate model have the resolution of 2 elements in crack location and $0.05 \mathrm{D}$ in crack depth, when the crack location and depth identification errors fall in $[-2,2]$ and $[-0.05,0.05]$ respectively, the identification results are considered to be accurate. From Figure 9, one can see all the samples were identified quite effectively. The samples located in the inside area were identified through updating for no more than 3 times, while for samples at the boundary, numbered 2, 3, and 6, needed updating for 4 to 5 times. As for the identification accuracy, from Table 3 , one can see that all the crack parameters of the under-test samples were accurately identified, except the crack location of sample 1, which has been identified as the 32th element. The error is thought to be acceptable, considering the resolution of crack locations. In addition, only after one updating step, the update process was stopped. The identification accuracy can be improved if more severe criterions are set, but it will lead to more updating steps. So, there is a 
trade-off between identification accuracy and efficiency. In view of all the identification results and the error factors, it can be concluded that the proposed crack identification method based on Kriging surrogate model performs quite well for the above unpolluted samples.

To study the robustness of the identification method, each sample was now added with noise. The noise-polluted response $\mathbf{y}_{\mathrm{N}}$ can be expressed as [61]:

$$
\mathbf{y}_{\mathrm{N}}=\mathbf{y}+L_{\mathrm{N}} \sigma_{\mathrm{y}} \mathbf{s}
$$

where $L_{N}$ is a number within $(0,1)$ that represents the noise level, which was selected as $5 \%$ in this work; $\sigma_{\mathrm{y}}$ is the standard deviation of original response $\mathrm{y}$ after noise is added; and $\mathbf{s}$ is an N-length vector of normally distributed random numbers with zero mean and unit variance. Figure 10 and Table 4 show the update process and identification results of the under-test samples with $5 \%$ noise.

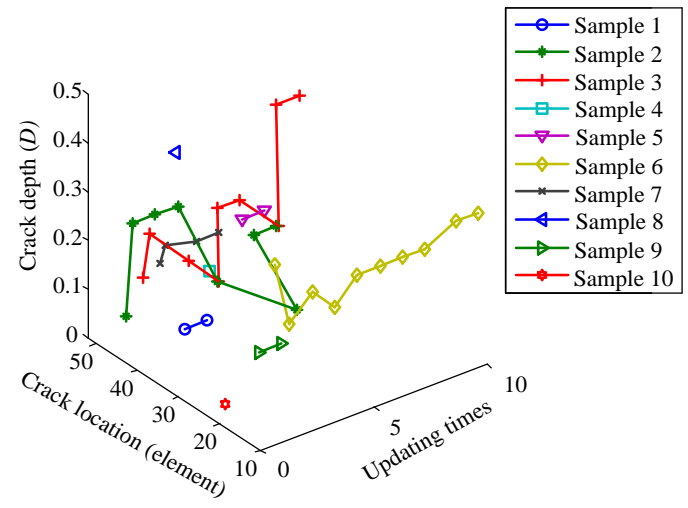

(a)

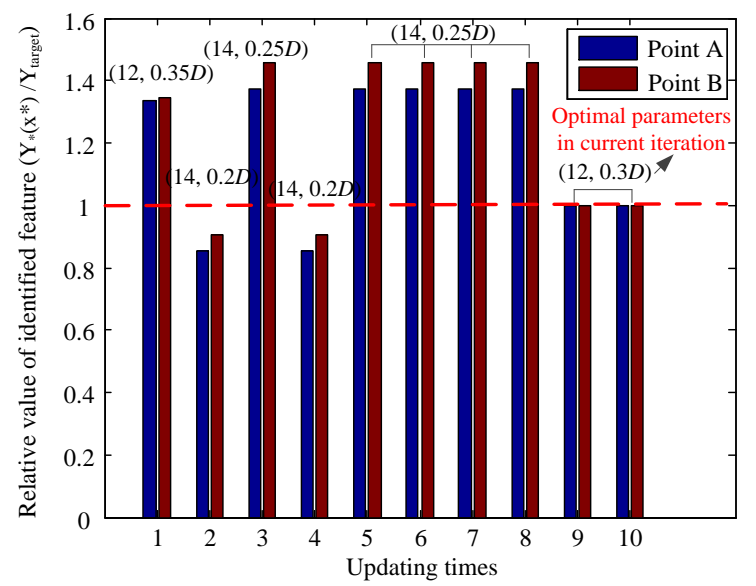

(b)

Figure 10. Update process of the under-test samples with $5 \%$ noise. (a) Identification process for all samples; (b) identification process and corresponding value of identified feature for sample 6.

Table 4. Crack identification results of the under-test samples with 5\% noise.

\begin{tabular}{|c|c|c|c|c|c|c|}
\hline \multirow[b]{2}{*}{$\begin{array}{c}\text { Under-Test } \\
\text { Sample } \\
\text { Number }\end{array}$} & \multicolumn{2}{|c|}{ Actual Parameters } & \multicolumn{2}{|c|}{ Identified Results } & \multirow[b]{2}{*}{$\begin{array}{l}\text { Updating } \\
\text { Times }\end{array}$} & \multirow{2}{*}{$\begin{array}{l}\text { Criterion Values } \\
\text { for the Final } \\
\text { Updated Model } \\
\left(C_{1}, C_{2}\right)\end{array}$} \\
\hline & $\begin{array}{c}\text { Crack } \\
\text { Location } \\
\text { (Element) }\end{array}$ & $\begin{array}{c}\text { Crack } \\
\text { Depth }(D)\end{array}$ & $\begin{array}{c}\text { Crack } \\
\text { Location } \\
\text { (Element) }\end{array}$ & $\begin{array}{c}\text { Crack } \\
\text { Depth }(D)\end{array}$ & & \\
\hline 1 & 34 & 0.1 & 34 & 0.1 & 2 & $(1,1)$ \\
\hline 2 & 46 & 0.05 & 50 & 0.1 & 8 & $(1,0.95)$ \\
\hline 3 & 50 & 0.35 & 50 & 0.35 & 9 & $(1,1)$ \\
\hline 4 & 28 & 0.25 & 28 & 0.25 & 1 & $(0.99,0.99)$ \\
\hline 5 & 20 & 0.4 & 20 & 0.4 & 2 & $(1,1)$ \\
\hline 6 & 12 & 0.3 & 12 & 0.3 & 10 & $(1,1)$ \\
\hline 7 & 42 & 0.2 & 42 & 0.2 & 4 & $(1,1)$ \\
\hline 8 & 38 & 0.45 & 36 & 0.45 & 1 & $(1,0.96)$ \\
\hline 9 & 16 & 0.15 & 16 & 0.15 & 2 & $(1,1)$ \\
\hline 10 & 24 & 0 & 24 & 0 & 1 & $(1,1)$ \\
\hline
\end{tabular}

Compared with the update process in Figure 9, from Figure 10 one can see that much more updating times are required for the samples at the boundary numbered 2, 3 and 6 with $5 \%$ noise, while the updating times for the non-boundary area are more or less the same. On the identification accuracy of the results in Table 4, there were some errors in samples 2 and 8. For sample 8, the reason for the error was the same as sample 1 without noise shown in Table 3, which was the relaxed threshold of the stop criterions. While for sample 2, the reason for the identification error was the prediction error at the 
boundary. Therefore, noise mainly affects the identification efficiency and accuracy for samples at the boundary, which can be improved by adding more samples at the boundary to reduce the prediction error. For the non-boundary cases, the proposed method is robust. To conclude, after proper sampling plan and adding samples, the proposed method is efficient, accurate and robust.

\section{Conclusions}

A new crack identification method is proposed for rotors with a breathing crack based on the Kriging surrogate model using the crack induced super-harmonic responses from two measurement points. Numerical experiments were carried out to investigate the performance of the proposed method based on a validated finite element rotor model with a breathing crack. The work in this paper validates the feasibility of the proposed method for crack identification in rotors. The results clearly show its effectiveness and accuracy. In addition, the presented method is robust to noise. Only a small number of samples are needed to construct the Kriging model, which reduces the cost of experiments or simulations. Furthermore, only two measurement points are required and this will be very useful for real applications. The two measurement points can be arranged at the bearing pedestals, which is quite convenient. However, only $2 \times$ components are considered to establish the surrogate model. To improve the reliability of the method for real rotors, more crack features should be applied. In addition, only one transverse crack with two crack parameters is considered. Multiple cracks with complex crack parameters may appear in real applications. Though the identification process is almost the same, much more effort is required for multi-crack situations, which will be studied in the near future combined with other efficient optimization methods.

Author Contributions: Conceptualization, Y.L.; Funding acquisition, Y.L.; Investigation, Z.L.; Methodology, Z.L. and H.O.; Validation, Z.L.; Writing-original draft, Z.L.; Writing-review \& editing, Y.L. and H.O.

Funding: This study was supported by the National Natural Science Foundation of China (51875416), the China Postdoctoral Science Foundation (2018M632928), and the Open Fund of Hubei Key Laboratory of Mechanical Transmission and Manufacturing Engineering (2018A08).

Conflicts of Interest: The authors declare no conflict of interest.

\section{References}

1. Bovsunovsky, A.; Surace, C. Non-linearities in the vibrations of elastic structures with a closing crack: A state of the art review. Mech. Syst. Signal Process. 2015, 62, 129-148. [CrossRef]

2. Fan, W.; Qiao, P. Vibration-based damage identification methods: A review and comparative study. Struct. Health Monit. 2011, 10, 83-111. [CrossRef]

3. Kumar, C.; Rastogi, V. A Brief Review on Dynamics of a Cracked Rotor. Int. J. Rotat. Mach. 2009, 2009, 1-6. [CrossRef]

4. Papadopoulos, C.A. The strain energy release approach for modeling cracks in rotors: A state of the art review. Mech. Syst. Signal Process. 2008, 22, 763-789. [CrossRef]

5. Yan, Y.J.; Cheng, L.; Wu, Z.Y.; Yam, L.H. Development in vibration-based structural damage detection technique. Mech. Syst. Signal Process. 2007, 21, 2198-2211. [CrossRef]

6. Carden, E.P.; Fanning, P. Vibration Based Condition Monitoring: A Review. Struct. Health Monit. 2004, 3 , 355-377. [CrossRef]

7. Sabnavis, G.; Kirk, R.G.; Kasarda, M.; Quinn, D. Cracked shaft detection and diagnostics: A literature review. Shock Vib. Dig. 2004, 36, 287. [CrossRef]

8. Sekhar, A.S. Model-based identification of two cracks in a rotor system. Mech. Syst. Signal Process. 2004, 18, 977-983. [CrossRef]

9. Pennacchi, P.; Bachschmid, N.; Vania, A. A model-based identification method of transverse cracks in rotating shafts suitable for industrial machines. Mech. Syst. Signal Process. 2006, 20, 2112-2147. [CrossRef]

10. Söffker, D.; Wei, C.; Wolff, S.; Saadawia, M.S. Detection of rotor cracks: Comparison of an old model-based approach with a new signal-based approach. Nonlinear Dyn. 2016, 83, 1153-1170. [CrossRef] 
11. Singh, S.; Tiwari, R. Model-Based Switching-Crack Identification in a Jeffcott Rotor With an Offset Disk Integrated With an Active Magnetic Bearing. J. Dyn. Syst. Meas. Control 2016, 138, 31006. [CrossRef]

12. Saridakis, K.M.; Chasalevris, A.C.; Papadopoulos, C.A.; Dentsoras, A.J. Applying neural networks, genetic algorithms and fuzzy logic for the identification of cracks in shafts by using coupled response measurements. Comput. Struct. 2008, 86, 1318-1338. [CrossRef]

13. Xiang, J.; Zhong, Y.; Chen, X.; He, Z. Crack detection in a shaft by combination of wavelet-based elements and genetic algorithm. Int. J. Solids Struct. 2008, 45, 4782-4795. [CrossRef]

14. He, J.; Yang, J.; Wang, Y.; Waisman, H.; Zhang, W. Probabilistic Model Updating for Sizing of Hole-Edge Crack Using Fiber Bragg Grating Sensors and the High-Order Extended Finite Element Method. Sensors 2016, 16, 1956. [CrossRef] [PubMed]

15. Waisman, H.; Chatzi, E.; Smyth, A.W. Detection and quantification of flaws in structures by the extended finite element method and genetic algorithms. Int. J. Numer. Methods Eng. 2010, 82, 303-328. [CrossRef]

16. Cavalini, A.A., Jr.; Sanches, L.; Bachschmid, N.; Steffen, V., Jr. Crack identification for rotating machines based on a nonlinear approach. Mech. Syst. Signal Process. 2016, 79, 72-85. [CrossRef]

17. Vashisht, R.K.; Peng, Q. Crack detection in the rotor ball bearing system using switching control strategy and Short Time Fourier Transform. J. Sound Vib. 2018, 432, 502-529. [CrossRef]

18. Qi, B.; Kong, Q.; Qian, H.; Patil, D.; Lim, I.; Li, M.; Liu, D.; Song, G. Study of Impact Damage in PVA-ECC Beam under Low-Velocity Impact Loading Using Piezoceramic Transducers and PVDF Thin-Film Transducers. Sensors 2018, 18, 671. [CrossRef] [PubMed]

19. Chen, J.; Chen, G.; Chen, B.; Li, Z.; Pan, J.; Zi, Y.; Yuan, J.; He, Z. Wavelet transform based on inner product in fault diagnosis of rotating machinery: A review. Mech. Syst. Signal Process. 2016, 70-71, 1-35. [CrossRef]

20. Hou, Q.; Ren, L.; Jiao, W.; Zou, P.; Song, G. An Improved Negative Pressure Wave Method for Natural Gas Pipeline Leak Location Using FBG Based Strain Sensor and Wavelet Transform. Math. Probl. Eng. 2013, 2013, 1-8. [CrossRef]

21. Xu, Y.; Luo, M.; Li, T.; Song, G. ECG Signal De-noising and Baseline Wander Correction Based on CEEMDAN and Wavelet Threshold. Sensors 2017, 17, 2754. [CrossRef] [PubMed]

22. Elbouchikhi, E.; Choqueuse, V.; Amirat, Y.; Benbouzid, M.E.H.; Turri, S. An Efficient Hilbert-Huang Transform-based Bearing Faults Detection in Induction Machines. IEEE Trans. Energy Convers. 2017, 32, 401-413. [CrossRef]

23. Chen, B.; Hei, C.; Luo, M.; Ho, M.S.; Song, G. Pipeline two-dimensional impact location determination using time of arrival with instant phase (TOAIP) with piezoceramic transducer array. Smart Mater. Struct. 2018, 27, 105003. [CrossRef]

24. Chandra, N.H.; Sekhar, A.S. Fault detection in rotor bearing systems using time frequency techniques. Mech. Syst. Signal Process. 2016, 72, 105-133. [CrossRef]

25. Sampaio, D.L.; Nicoletti, R. Detection of cracks in shafts with the Approximated Entropy algorithm. Mech. Syst. Signal Process. 2016, 72, 286-302. [CrossRef]

26. Shravankumar, C.; Tiwari, R. Detection of a fatigue crack in a rotor system using full-spectrum based estimation. Sadhana 2016, 41, 239-251. [CrossRef]

27. Yang, L.; Chen, X.; Wang, S. A novel amplitude-independent crack identification method for rotating shaft. Proc. Inst. Mech. Eng. Part C J. Mech. Eng. Sci. 2018, 232, 4098-4112. [CrossRef]

28. Xie, J.; Cheng, W.; Zi, Y.; Zhang, M. Phase-based spectrum analysis method for identifying weak harmonics. J. Vib. Control 2018, 24, 5585-5596. [CrossRef]

29. Dong, H.B.; Chen, X.F.; Li, B.; Qi, K.Y.; He, Z.J. Rotor crack detection based on high-precision modal parameter identification method and wavelet finite element model. Mech. Syst. Signal Process. 2009, 23, 869-883. [CrossRef]

30. Liu, F.; Gao, S.; Han, H.; Tian, Z.; Liu, P. Interference reduction of high-energy noise for modal parameter identification of offshore wind turbines based on iterative signal extraction. Ocean Eng. 2019. [CrossRef]

31. Rubio, L.; Fernández-Sáez, J.; Morassi, A. Identification of two cracks in a rod by minimal resonant and antiresonant frequency data. Mech. Syst. Signal Process. 2015, 60, 1-13. [CrossRef]

32. Rahman, A.G.A.; Ismail, Z.; Noroozi, S.; Chao, O.Z. Study of open crack in rotor shaft using changes in frequency response function phase. Int. J. Damage Mech. 2013, 22, 791-807. [CrossRef]

33. Seo, Y.; Lee, C.; Park, K.C. Crack Identification in a Rotating Shaft via the Reverse Directional Frequency Response Functions. J. Vib. Acoust. 2009, 131, 11012. [CrossRef] 
34. Hou, Q.; Jiao, W.; Ren, L.; Cao, H.; Song, G. Experimental study of leakage detection of natural gas pipeline using FBG based strain sensor and least square support vector machine. J. Loss Prev. Process Ind. 2014, 32, 144-151. [CrossRef]

35. Zapico-Valle, J.L.; Rodríguez, E.; García-Diéguez, M.; Cortizo, J.L. Rotor crack identification based on neural networks and modal data. Meccanica 2014, 49, 305-324. [CrossRef]

36. Mottershead, J.E.; Link, M.; Friswell, M.I. The sensitivity method in finite element model updating: A tutorial. Mech. Syst. Signal Process. 2011, 25, 2275-2296. [CrossRef]

37. Alkayem, N.F.; Cao, M.; Zhang, Y.; Bayat, M.; Su, Z. Structural damage detection using finite element model updating with evolutionary algorithms: A survey. Neural Comput. Appl. 2018, 30, 389. [CrossRef]

38. Shabbir, F.; Khan, M.; Ahmad, N.; Tahir, M.; Ejaz, N.; Hussain, J. Structural Damage Detection with Different Objective Functions in Noisy Conditions Using an Evolutionary Algorithm. Appl. Sci. 2017, 7, 1245. [CrossRef]

39. Rocchetta, R.; Broggi, M.; Huchet, Q.; Patelli, E. On-line Bayesian model updating for structural health monitoring. Mech. Syst. Signal Process. 2018, 103, 174-195. [CrossRef]

40. Bi, S.; Broggi, M.; Beer, M. The role of the Bhattacharyya distance in stochastic model updating. Mech. Syst. Signal Process. 2019, 117, 437-452. [CrossRef]

41. Patel, T.H.; Zuo, M.J.; Darpe, A.K. Vibration response of coupled rotor systems with crack and misalignment. Proc. Inst. Mech. Eng. Part C J. Mech. Eng. Sci. 2011, 225, 700-713. [CrossRef]

42. Reddy, M.C.S.; Sekhar, A.S. Detection and monitoring of coupling misalignment in rotors using torque measurements. Measurement 2015, 61, 111-122. [CrossRef]

43. Jiang, T.; Kong, Q.; Patil, D.; Luo, Z.; Huo, L.; Song, G. Detection of Debonding Between Fiber Reinforced Polymer Bar and Concrete Structure Using Piezoceramic Transducers and Wavelet Packet Analysis. IEEE Sens. J. 2017, 17, 1992-1998. [CrossRef]

44. Li, D.; Liang, Y.; Feng, Q.; Song, G. Load monitoring of the pin-connected structure based on wavelet packet analysis using piezoceramic transducers. Measurement 2018, 122, 638-647. [CrossRef]

45. Xiang, J.; Zhong, Y. A Novel Personalized Diagnosis Methodology Using Numerical Simulation and an Intelligent Method to Detect Faults in a Shaft. Appl. Sci. 2016, 6, 414. [CrossRef]

46. Gómez, M.J.; Castejón, C.; García-Prada, J.C. Crack detection in rotating shafts based on 3× energy: Analytical and experimental analyses. Mech. Mach. Theory 2016, 96, 94-106. [CrossRef]

47. Lv, Y.; Yuan, R.; Song, G. Multivariate empirical mode decomposition and its application to fault diagnosis of rolling bearing. Mech. Syst. Signal Process. 2016, 81, 219-234. [CrossRef]

48. Lv, Y.; Yuan, R.; Wang, T.; Li, H.; Song, G. Health degradation monitoring and early fault diagnosis of a rolling bearing based on CEEMDAN and improved MMSE. Materials 2018, 11, 1009. [CrossRef]

49. Yuan, R.; Lv, Y.; Song, G. Multi-Fault Diagnosis of Rolling Bearings via Adaptive Projection Intrinsically Transformed Multivariate Empirical Mode Decomposition and High Order Singular Value Decomposition. Sensors 2018, 18, 1210. [CrossRef]

50. Guo, C.; Yan, J.; Yang, W. Crack detection for a Jeffcott rotor with a transverse crack: An experimental investigation. Mech. Syst. Signal Process. 2017, 83, 260-271. [CrossRef]

51. Sacks, J.; Welch, W.J.; Mitchell, T.J.; Wynn, H.P. Design and analysis of computer experiments. Stat. sci. 1989, 4, 409-423. [CrossRef]

52. Nobari, A.; Ouyang, H.; Bannister, P. Uncertainty quantification of squeal instability via surrogate modelling. Mech. Syst. Signal Process. 2015, 60, 887-908. [CrossRef]

53. Han, F.; Guo, X.; Gao, H. Bearing parameter identification of rotor-bearing system based on Kriging surrogate model and evolutionary algorithm. J. Sound Vib. 2013, 332, 2659-2671. [CrossRef]

54. Gao, H.; Guo, X.; Ouyang, H.; Han, F. Crack Identification of Cantilever Plates Based on a Kriging Surrogate Model. J. Vib. Acoust. 2013, 135, 51012. [CrossRef] [PubMed]

55. Darpe, A.K.; Gupta, K.; Chawla, A. Coupled bending, longitudinal and torsional vibrations of a cracked rotor. J. Sound Vib. 2004, 269, 33-60. [CrossRef]

56. Lu, Z.; Dong, D.; Ouyang, H.; Cao, S.; Hua, C. Localization of breathing cracks in stepped rotors using super-harmonic characteristic deflection shapes based on singular value decomposition in frequency domain. Fatigue Fract. Eng. Mater. Struct. 2017, 40, 1825-1837. [CrossRef]

57. Newmark, N.M. A method of computation for structural dynamics. J. Eng. Mech. Div. 1959, 85, 67-94.

58. Sinou, J.; Lees, A.W. The influence of cracks in rotating shafts. J. Sound Vib. 2005, 285, 1015-1037. [CrossRef] 
59. Forrester, A.; Sobester, A.; Keane, A. Engineering Design Via Surrogate Modelling: A Practical Guide; John Wiley \& Sons: Hoboken, NJ, USA, 2008.

60. Zhang, X.; Gao, R.X.; Yan, R.; Chen, X.; Sun, C.; Yang, Z. Multivariable wavelet finite element-based vibration model for quantitative crack identification by using particle swarm optimization. J. Sound Vib. 2016, 375, 200-216. [CrossRef]

61. Mao, Y.M.; Guo, X.L.; Zhao, Y. A state space force identification method based on Markov parameters precise computation and regularization technique. J. Sound Vib. 2010, 329, 3008-3019. [CrossRef] 